\title{
LEVANTAMENTO SOBRE A UTILIZAÇÃO DA CONTABILIDADE NAS PROPRIEDADES PECUÁRIAS DE PEQUENO E MÉDIO PORTE DO MUNICÍPIO DE TANGARÁ DA SERRA - MT.
}

\author{
Deise Caroline Sonsin ${ }^{1}$ \\ Laércio Juarez Melz ${ }^{2}$ \\ Cleiton Franco ${ }^{3}$
}

\section{RESUMO}

O estudo busca demonstrar a importância da Contabilidade Rural para o pequeno e médio produtor rural, como ferramenta gerencial que permitem o planejamento e o controle orçamentário para tomada de decisões por meio do sistema contábil. Essas informações são muito importantes para planejar e acompanhar a diversificação e a modernização deste setor. Foi desenvolvida a pesquisa de campo, através de entrevistas aplicadas a proprietários rurais situados no município de Tangará da Serra - MT, e a escritórios contábeis também situados no município. Concluiu-se que a contabilidade gerencial nestas propriedades é pouco utilizada. Os serviços ou ferramentas mais utilizadas são para fins tributários, trabalhistas, declarações, entre outros. Poucos escritórios contábeis de Tangará da Serra possuem profissionais especializados nesta área.

PALAVRAS-CHAVE: Contabilidade rural. Produtor rural. Ferramenta de administração.

\section{INTRODUÇÃO}

Devido ao grande avanço tecnológico provocado pela economia, parte das atividades econômicas do Brasil sentiu necessidade de buscar cada vez mais por inovações e qualificações de vários setores, buscando suprir suas necessidades mantendo um controle econômico adequado com o mercado.

Enquadrada nessas atividades na qual foram afetadas esta a agropecuária que tornousse mais competitiva no decorrer dos anos buscando a qualificação deste setor de acordo com as exigências do mercado, procurando aumentar assim sua produtividade e reduzir seus custos. Dessa forma a contabilidade vem desempenhando um importante papel, como ferramenta de controle gerencial, auxiliando assim nas tomadas de decisões, dando forma e característica de empresa às propriedades agropecuárias.

A pesquisa teve, como objetivos específicos: a) identificar quais as ferramentas gerenciais utilizadas por pequenas e médias propriedades pecuárias; b) verificar o que a literatura aponta como importante para essa atividade; c) identificar quais as ferramentas

\footnotetext{
${ }^{1}$ Acadêmica do curso de Ciências Contábeis da UNEMAT - Campus de Tangará da Serra, deisesonsin@ hotmail.com

${ }^{2}$ Mestre em Engenharia de Produção (UFSCar), Professor do Departamento de Ciências da UNEMAT - Campus de Tangará da Serra, laercio@unemat.br

${ }^{3}$ Mestre em Economia (UFMT), Professor do Departamento de Ciências da UNEMAT - Campus de Tangará da Serra, cleitonfranco@unemat.br
} 
gerenciais para a atividade pecuária; d) verificar se os escritórios contábeis oferecem essas ferramentas gerenciais aos produtores. O problema da pesquisa foi definido como: quais as ferramentas gerenciais utilizadas na atividade pecuária de pequenas e médias propriedades do município de Tangará da Serra - MT? Devido ser um trabalho de caráter investigativo, fica descartada a sugestão de hipótese.

\section{REFERENCIAL TEÓRICO}

\subsection{Atividade rural}

Segundo Nepomuceno (2004, p. 19) "Na atividade rural, os termos e as expressões sinonímicos variam de região para região e, até mesmo, dentro de uma mesma região usa-se, alternadamente, denominações variadas."

Logo alguns autores conceituam empresas rurais como:

Marion (2005, p. 24) "Empresas rurais são aquelas que exploram a capacidade produtiva do solo por meio do cultivo da terra, da criação de animais e da transformação de determinados produtos agrícolas".

Já para Crepaldi (2005, p. 25) "Empresa rural é a unidade de produção em que são exercidas atividades que dizem respeito a culturas agrícolas, criação de gado ou culturas florestais, com a finalidade de obtenção de renda".

Partindo da idéia acima citada por Marion e Crepaldi (2005), nota-se que as atividades rurais podem ser exploradas de várias maneiras, tanto para o próprio consumo e sobrevivência, como por várias empresas que exercem suas atividades neste setor.

\subsection{Gestão e administração da atividade rural}

Um gestor rural, ou empresário rural acredita que para obter sucesso na agropecuária, é necessário ter sensibilidade, conhecimento técnico e acima de tudo competência para levantar diagnósticos sobre a empresa, e assim tomar decisões.

Segundo Crepaldi (2005, p.24):

O conhecimento das condições de mercado e dos recursos naturais dá ao produtor rural os elementos básicos para o desenvolvimento de sua atividade econômica. Cabe a ele decidir o quê, quanto e como produzir, controlar a ação após iniciar a atividade e, por último, avaliar os resultados alcançados e compará-los com os previstos inicialmente.

Continuando, Crepaldi (2005, p. 55) ressalta que:

A administração cuida em determinar que os produtos e serviços são necessários e em colocá-los nas mãos dos consumidores. A administração financeira trata das decisões sobre planejamento a fim de atingir o objetivo de maximizar a riqueza dos proprietários rurais. Como as finanças estão envolvidas em todos os aspectos 
operacionais da Empresa Rural, os gerentes não financeiros, não podem efetivar suas obrigações sem informações financeiras.

Desta forma o administrador rural, passar a ter tarefas no seu cotidiano, que o leva a tomadas de decisões sobre que produto produzir, acompanhado o mercado econômico e avaliando seu estabelecimento rural, para ver se o mesmo está apto a produzir certo produto; o quanto produzir, considerando num conjunto de fatores a quantidade de terra que seu estabelecimento dispõe e a quantia de capital terá para manter sua mão de obra; como produzir, ou seja, buscar analisar e estudar o produto na qual estará produzindo, buscando atingir os melhores meios de produção; controlar o desenvolvimento da safra, verificando se todo o processo de produção (plantio, colheita e produto final), está sendo aplicado corretamente e finalmente avaliar os resultados obtidos na mesma, analisando se na apuração do resultado final a empresa obteve lucro ou prejuízo, demonstrando de maneira clara que razões fizeram com que este resultado fosse atingido, Crepaldi (2005).

Conforme Crepaldi (2005, p.25)

A administração rural é, portanto, o conjunto de atividades que facilita aos produtores rurais a tomada de decisões ao nível de sua unidade de produção, a empresa agrícola, com o fim de obter melhor resultado econômico, mantendo a produtividade da terra.

Também cabe ao gestor rural, cumprir com a. gestão orçamentária, que é de fundamental importância. Ela ajuda o gestor a ter previsão em relação ao montante do custo que terá em determinada produção, conforme Nepomuceno (2004).

Seguindo este raciocínio Nepomuceno (2004, p. 91) afirma que:

A orçamentação é também, e, sobretudo, uma ferramenta de aperfeiçoamento da administração na atividade rural, que permite trabalhar com os olhos voltados para o que vai acontecer. Equivale a dizer que não se dará passos no escuro, isto é, na medida do possível.

Segundo Santos, Marion e Segatti (2002, p. 143): “o orçamento é o levantamento prévio de receitas, custos, despesas e investimentos, cuja finalidade é dar consistência ao planejamento estratégico da empresa rural e conseqüentemente ao planejamento operacional".

\subsection{A finalidade da contabilidade rural}

Conforme Calderelli (2003, p. 180), Contabilidade Rural é “aquela que tem suas normas baseadas na orientação, controle e registro dos atos e fatos ocorridos e praticados por uma empresa cujo objetivo de comércio ou indústria seja agricultura ou pecuária".

Logo nota-se que para uma empresa rural ser bem sucedida é necessário que ela se submeta a uma administração eficiente, buscando alcançar todos os itens, ou regras que a 
mantenham no mercado. Tais regras podem ser especificadas como o conhecimento do negócio na qual está atuando, estar buscando sempre a modernização e a especialização do setor e estar por dentro da quantia de capital envolvido no negócio.

Segundo Crepaldi (2005, p.19):

A Contabilidade Rural no Brasil é pouco utilizada, tanto pelos empresários quanto pelos contadores. Isto acontece devido ao desconhecimento por parte destes empresários da importância das informações obtidas através da contabilidade, da maior segurança e clareza que estas informações proporcionam nas tomadas de decisões. Isto acontece também em função da mentalidade conservadora da maioria dos agropecuaristas que persistem em manter controles baseados em sua experiência adquirida com o passar dos anos. Dessa forma abrem mão de dados reais que poderiam ser obtidos através da contabilidade.

Conforme Crepaldi (2005) relata, grande parte dos produtores rurais vê a contabilidade como uma ciência complexa, utilizada somente para efetuar declarações de imposto de renda, sem nenhum retorno voltado a prática.

Na concepção de Marion (2005, p. 25), “A contabilidade pode ser estudada de modo geral (para todas as empresas) ou particular (aplicada a certo ramo de atividade ou setor da economia)".

\subsection{Controle gerencial interno}

Obter informações gerenciais que auxiliam nas tomadas de decisões, tem sido uma das maiores dificuldades enfrentadas pelos produtores rurais devido à falta de controle interno, que por sua vez permite adquirir dados consistentes e reais.

Crepaldi (2005, p. 69) afirma que:

A filosofia de fazenda-empresa baseia-se em uma gerência moderna e eficiente. Dentro da administração geral de uma Empresa Rural, a gerência corresponde ao coração de todo o sistema, ou seja, tem a responsabilidade de funcionamento de toda a máquina produtiva.

De acordo com Crepaldi (2005, p.65):

O que o administrador precisa saber é como está a rentabilidade de sua atividade produtiva. Quais são os resultados obtidos e como eles pode ser otimizados por meio de avaliação dos resultados, fontes de receitas e tipos de despesas? Como melhoras as receitas e reduzir as despesas? Essa analise só será possível a partir do momento em que se sabe onde estamos gastando os recursos e onde estamos gerando receitas.

Para saber onde estão sendo gastos os recursos e onde estão sendo geradas as receitas é necessário que a entidade rural tenha um controle gerencial adequado, o gestor necessita ter em mãos todos os dados necessários para o levantamento e definição da situação econômica e financeira da empresa.

Vale ressaltar que para se obter bom controle gerencial é necessário que a entidade tenha um bom demonstrativo financeiro. Com uma escrituração simples de um plano de 
contas que contenha as contas necessárias como despesas e receitas. Na qual também poderá cadastrar mais itens conforme for necessário. O que possibilitará a ele alcançar os resultados esperados pela entidade. Nota-se que este é um dos métodos mais simples e dinâmicos de controle, que permite avaliar o andamento das atividades com mais rapidez.

Enfim seguindo nesta linha de raciocínio, Crepaldi (2005, p.65) afirma:

\begin{abstract}
Existem diversas técnicas de controle que podem auxiliar na obtenção dessas informações gerenciais. O importante é saber em qual nível de detalhamento e sofisticação de seu empreendimento se encaixa. O primeiro passo é partir do principio de que o modelo adotado deve utilizar dados que sua estrutura organizacional consiga gerar normalmente.
\end{abstract}

\title{
2.5 Ferramentas gerenciais
}

Para o processo de gerenciamento, a empresa pecuária pode utilizar algumas ferramentas gerenciais, tais como: análise de custo-volume-lucro, análise tributária, análise de recursos humanos e fluxo de caixa. Essas ferramentas são apresentadas nas seções seguintes.

\subsubsection{Análise do custo, volume e lucro}

Dentre vários conceitos, podem-se definir custos como um conjunto que engloba vários procedimentos administrativos, que busca registrar um valor efetivo da remuneração dos fatores de produção, empregados nas atividades pecuárias, Nepomuceno (2004).

A análise de custo, volume, lucro é uma ferramenta de avaliação utilizada pelos gerentes, na qual examina o comportamento das receitas, dos custos totais, dos resultados das operações decorrentes nos níveis de vendas, dos preços de venda, custos variáveis ou custos fixos por unidade. Os administradores usufruem esta análise como uma ferramenta para auxiliá-los a responder questões, quanto ao que acontecerá com o lucro se houverem modificações nos preços de venda, nos custos e no volume vendido, Horngren et al (1999).

Os custos têm como objetivo auxiliar nas tomadas de decisões, controle e organização, ajudando o administrador a chegar a atividades e operações de menor valor, mais lucrativas e vantajosas. Também permite um levantamento correto da valorização dos estoques para a apuração do resultado final de cada exercício, conforme cada criação. Oferece ao produtor maior confiança do que, quando e como produzir, através de orçamentos, ou projeções dos custos que o mesmo irá ter em determinada produção.

De acordo com Marion (p.62, 1996):

Um sistema de custos completo tem atualmente objetivos amplos e bem definidos, que refletem sua importância como ferramenta básica para a administração de qualquer empreendimento, especialmente na agropecuária, onde os espaços de tempo entre produção e vendas, ou seja, entre custos e receitas, fogem a simplicidades de outros tipos de negócio, exigindo técnicas especiais para apresentação não dos custos, mas dos resultados econômicos do empreendimento. 
Os custos podem ser classificados, tanto em relação a sua identificação, quanto a sua variação quantitativa.

Em relação a sua identificação estão os custos diretos e indiretos. Custos diretos são aqueles relacionados diretamente ao produto, e podem ser identificados através de um sistema e um método de medição, como: mão-de-obra, sementes ou rações, gastos com funcionamento e manutenção de máquinas agrícolas, etc. Custos indiretos são aqueles necessários a produção, e que são alocados por meio do sistema de rateio, como salários (administrativos, técnicos, chefias), pessoal e instalações, por exemplo, Megliorini (2007).

Já em relação a sua variação quantitativa estão os custos fixos e variáveis. Custos variáveis são aqueles que variam de acordo com a produção, como mão-de-obra direta, materiais diretos, horas-máquinas, etc. Custos fixos são aqueles que não se alteram, em relação a valor, independente do volume produzido, como depreciação de instalações, benfeitorias de acordo com Martins (2003).

\subsubsection{Análise tributária (fiscal)}

Segundo nos ensina Anceles (2001), a tributação dos rendimentos vindos da pecuária e da agricultura, que antes eram exercidas por pessoas jurídicas, passou a ter melhor incentivo a partir do decreto-lei $n^{\circ} 902 / 69$, que passou a tratar esta matéria com essa tributação nas pessoas físicas.

A partir de então surgiram vários aspectos tributários, onde os principais tributos que incidem sobre as atividades tanto agrícolas, quanto pecuária são: Imposto sobre a Propriedade Territorial Rural (ITR), Imposto sobre a Renda (IR), Imposto sobre Operações Relativas à Circulação de Mercadorias e sobre a Prestação de Serviços de Transporte Interestadual e Intermunicipal e de Comunicação (ICMS), conforme Anceles (2001).

O Imposto sobre a Propriedade Territorial Rural (ITR), conforme Anceles (2001), foi introduzido pela Constituição Federal de 1891, como imposto estadual, e somente em 1961, foi transferido para imposto de competência municipal através da Emenda Constitucional $\mathrm{n}^{\circ}$ 05. De acordo com a Lei $\mathrm{n}^{\circ}$ 9.393, de 19 de dezembro de 1996 :

Art. $1^{\circ}$ O Imposto sobre a Propriedade Territorial Rural - ITR, de apuração anual, tem como fato gerador a propriedade, o domínio útil ou a posse de imóvel por natureza, localizado fora da zona urbana do município, em $1^{\circ}$ de janeiro de cada ano.

Seguindo o art. 31 da Lei $\mathrm{n}^{\circ}$ 5.172, afirma que "Contribuinte do imposto é o proprietário do imóvel, o titular de seu domínio útil, ou o seu possuidor a qualquer título”. 
Quanto à declaração anual do ITR, o contribuinte, obrigatoriamente entregará em cada ano, o Documento de Informação e Apuração do ITR - DIAT, referente a cada propriedade, observando a data de entrega e as condições impostas pela Secretaria da Receita Federal.

Na tentativa de modificar o sistema de tributação da renda das atividades exercidas pelas pessoas físicas, procurando dar proteção aos produtores de pequeno porte, surgiu o Decreto-lei $n^{\circ}$ 902, de 1969, que consistia na redução da base de calculo do imposto sobre a renda.

Conforme art. 1 da lei $\mathrm{n}^{\circ} 8023$, de 12 de abril de 1990 "Art. $1^{\circ}$ Os resultados provenientes da atividade rural estarão sujeitos ao Imposto de Renda de conformidade com o disposto nesta lei”.

Essa lei que foi permitida somente no exercício de 1991, ano-calendário de 1990, substituiu o sistema de incentivo de multiplicadores, que também além de visar o mesmo efeito sobre a base de cálculo do imposto de renda, ajudava na redução a aplicação de recursos em fundo de suporte financeiro ao setor rural. Esse incentivo, no entanto foi revogado no ano de 1995, com o art. 36 da lei no 9.249/95.

Segundo Anceles (2001, p. 20):

De 1970 até o ano calendário de 1995, o resultado da exploração rural era obtido por uma das formas - estimada, escritural e contábil - definidas em função da receita bruta, desobrigando-se, ao máximo, de formalidades os pequenos agricultores. Do ano-calendário de 1996 em diante, simplifica-se o método de apuração do resultado dessa atividade, mediante escrituração de livro Caixa, qualquer que seja a receita bruta do ano. A falta do livro Caixa implica arbitramento do lucro em $20 \%$ da receita bruta do ano-calendário.

Assim fica claro que a atividade rural trabalha através do método de livro caixa, na qual deverá abranger as receitas, despesas de custeio, os investimentos, e os demais gastos que fazem parte da atividade onde o resultado final tem como objetivo o lucro (ganho), apesar de muitas vezes ser desfavorável demonstrando prejuízo. Esse método de apuração ocorrerá independente do tipo da atividade rural explorada ou do tamanho do imóvel.

Conforme Anceles (2001) o ICMS (Imposto sobre Operações Relativas à Circulação de Mercadorias e sobre a Prestação de Serviços de Transporte Interestadual e Intermunicipal e de Comunicação), foi criado em 1923 com a partir da Lei 4.625, atendendo as associações comerciais que pretendiam um papel líquido e certo, no intuito de facilitar os descontos das faturas de vendas industriais e comerciais nos bancos. A partir de 1934 este imposto não era aplicado somente a vendas mercantis, mais também a produtores em geral.

Para a definiç̧ão da estrutura do ICMS, surgiu a Lei Complementar ${ }^{\circ}$ n 87/96, que tem como definição as bases de cálculo, os fatos geradores, os casos de não incidência, a 
localização da operação e da prestação, bem como a compensação de crédito e a substituição tributária, e a sujeição passiva.

O Funrural (Fundo de Assistência ao Trabalhador Rural) é retido na fonte, ou seja, o comprador recolhe na guia de recolhimento do INSS (Instituto Nacional de Seguridade Social), o valor a ser descontado do produtor rural.

Já as Taxas de Serviços Cadastrais baseia-se no decreto-lei $n^{\circ} 57$, de 1966, na Lei $\mathrm{n}^{\circ}$ 6.746/79, e decreto-lei $\mathrm{n}^{\mathrm{o}}$ 1.959/82. É recolhido através de DARF (Documento de Arrecadação de Receitas Federais), com destino ao INCRA (Instituto Nacional de Colonização e Reforma Agrária).

A contribuição Sindical Rural é recolhida uma vez por ano, através da guia patronal e dos empregados. A guia patronal é recolhida ao CNA (Confederação Nacional da Agricultura), baseada no decreto-lei nº 1.166/71. Já a contribuição dos empregados deverá ser recolhida ao CONTAG (Confederação Nacional dos Trabalhadores na Agricultura), conforme art. 580 da Consolidação das Leis do Trabalho.

Por fim a Contribuição ao SENAR (Serviço Nacional de Aprendizagem Rural) é recolhido junto com a guia do INSS pelos estabelecimentos agroindustriais, através da Lei $n^{\circ}$ $8.315 / 91$.

\subsubsection{Análise de Recursos Humanos}

Com um cenário mundial cada vez mais avançado e inovado, os sistemas agroindustriais avançaram cada vez mais as fronteiras nacionais. Sendo assim a competição entre as empresas tornam-se ainda mais acirradas, o que determina sua capacidade de crescer frente aos demais concorrentes, Batalha et al (2005).

De acordo com Batalha et al (2005), essa competição caminha em direção a gestão estratégica de recursos humanos, gestão de competências, acumulação do saber e gestão do capital intelectual. Todas essas proposições mostram o quanto o mercado de trabalho busca por profissionais mais qualificados, capacitados e aptos a alcançar os objetivos da entidade de modo eficaz.

Para que um profissional tenha um bom desempenho no mercado de trabalho, são sugeridas algumas competências essenciais na qual devem ser trabalhados, com recursos onde os trabalhares devem saber identificar, organizar, planejar e alocar.

Deve ser inter-pessoal, onde os mesmos devem saber trabalhar com outros profissionais em equipe. Buscar informações, na qual devem saber adquirir e usar essas informações. Buscar conhecer o sistema tecnológico com que trabalham e sempre buscar por tecnologia 
onde devem ter conhecimento para trabalhar com uma variedade de tecnologia, Batalha et al (2005).

\subsubsection{Fluxo de Caixa}

Segundo Martinovich (1996) é uma ferramenta gerencial de fundamental importância na tomada de decisões empresariais, na qual tem como objetivo a coleta de dados para análise de desempenho financeiro, e para realização de previsões orçamentárias.

Pode ser representado através de um quadro onde são destacados o período na qual esta sendo trabalhado e assim serão confrontados as entradas através de recebimentos ocorridos e saídas devido a pagamentos feitos em dinheiro neste período, Batalha (2009).

Também podem ser representados através de diagramas.

Segundo Batalha (2009, p.211):

O diagrama é representado por uma linha horizontal utilizada como escala de tempo e por vetores verticais, onde a orientação no sentido superior significa entrada de dinheiro e no sentido inferior saída de dinheiro. Em termos algébricos, os pagamentos serão negativos e os recebimentos serão positivos.

\section{METODOLOGIA}

Para a realização deste artigo, foi desenvolvida a pesquisa de campo, através de entrevistas aplicadas a proprietários rurais situados no município de Tangará da Serra - MT, e a escritórios contábeis também situados no município.

Foram realizados dois tipos de questionários, onde um foi aplicado em escritórios de contabilidade em geral, na qual todos prestam serviços e assessoria contábil no município de Tangará da Serra - MT, e o outro foi realizado em empresas de pecuária de pequeno e médio porte, também neste município. De acordo com a lista do CRC (Conselho Regional de Contabilidade) o município de Tangará da Serra - MT possui o total de 47 (quarenta e sete) escritórios contábeis, sendo que desse montante, somente 39 (trinta e nove) responderam a pesquisa, pois 3 (três) deles não realizam, não possuem atividades relacionadas a essa área, e 5 (cinco) não quiseram responder a entrevista.

Para chegar à seleção de produtores foi utilizado o "método bola de neve", na qual um informante culturalmente competente recomenda outros agentes-chaves de competência similar, dando seqüência ao processo de forma repetitiva a partir de novos incluídos, (MELZ, 2010). Desta forma as empresas rurais representaram um montante total de 243 (duzentos e quarenta e três) produtores. A pesquisa foi realizada conforme a disponibilidade dos mesmos em responder ao questionário. Deste montante, 221 (duzentos e vinte e um) responderam a entrevista, já os demais 22 (vinte e dois) opinaram por não responder. 
A pesquisa classifica-se como quantitativa e qualitativa. Quantitativa, pois, permitiu obter a quantificação dos resultados e a medição objetiva dos mesmos. Qualitativa, pois, é utilizada de forma direta e interativa em relação ao assunto estudado, proporcionando complementação e esclarecimento das informações coletadas.

Conforme lembra Both e Siqueira (2004) método qualitativo e quantitativo ocorreu na década de 80, e divide-se em várias etapas, como observação, raciocínio indutivo e dedutivo e experimentação. Tem como propósito dirigir pensamento relativamente concreto e maduro. Resultando na coleta e análise de dados de forma numérica. Tem grande importância em nosso meio social, sendo demonstrada de maneira fácil para os pesquisadores de outras áreas.

Também classifica-se como explicativa e descritiva, pois, buscou-se obter dados que identificassem a ocorrência de determinados fatores, além da presença de observação, classificação, interpretação, e a análise dos fatos registrados. A pesquisa de campo também será utilizada como forma de investigação no local onde se aplicará o projeto. E por fim a pesquisa bibliográfica, desenvolvida com base e matérias publicados em livros, jornais, revistas, internet, etc.

\section{RESULTADOS}

Os resultados descritos, foram alcançados a partir de dados coletados com base nos questionários aplicados aos escritórios de contabilidade e proprietários rurais residentes no município de Tangará da Serra localizado no estado do Mato Grosso.

\subsection{Características dos entrevistados}

Dos escritórios entrevistados, $87,18 \%$ deles consideram-se escritórios de pequeno porte, $12,82 \%$ escritórios de médio porte, e nenhum deles se consideram de grande porte. Quanto ao tempo de existência dos mesmos, constatou-se que 20,52\% dos escritórios entrevistados disseram atuar na área entre 01 a 05 anos, 71,79\%, prestam serviços entre 05 a 10 anos, 5,13\% atuam no município entre 10 a 15 anos, 2,56\% atuam entre 15 a 20 anos e nenhum dos entrevistados atuam no município há mais de 20 anos, conforme Tabela 01.

Tabela 01 - Tempo de atuação do escritório no município, em quantidade e \% de respostas, Tangará da Serra - MT, 2011. 


\begin{tabular}{ccc}
\hline 01 a 05 anos & 8 & 20,52 \\
05 a 10 anos & 28 & 71,79 \\
10 a 15 anos & 2 & 5,13 \\
15 a 20 anos & 1 & 2,56 \\
Mais de 20 anos & 0 & 0,00 \\
\hline \hline Total & 39 & 100 \\
\hline
\end{tabular}

Fonte: Dados da Pesquisa / 2011.

Já o número de funcionários dos escritórios entrevistados é formado por 84,62\%, que possuem de 01 a 10 funcionários; 15,38\%, entre 11 a 20 funcionários e nenhum deles possui mais de 20 funcionários.

Em relação à frequiência na qual os escritórios costumam prestar serviços de assessoria na área rural, 71, 79\%, disseram que a freqüência é pequena, 28,20\% responderam ter uma freqüência media, e nenhum estabelecimento respondeu ter uma freqüência de grande porte.

Relacionando às diversas dificuldades enfrentadas pelos escritórios em atender aos produtores rurais, surgiram as mais variadas respostas, dentre elas destacam-se: a) a falta de organização dos produtores, em geral, com os documentos necessários para a realização dos serviços contábeis de maneira correta. Muitas vezes os mesmos são entregues em atrasos, dificultando e muitas vezes impedindo a prestação dos serviços no devido prazo, e o levantamento das informações necessárias, gerando, acúmulo de trabalho em determinada época do ano; b) devido ritmo freqüente em relação às mudanças nas leis, acabam por gerar desconfianças por parte dos produtores, para com os contadores, causando assim um grande desconforto entre ambos; c) o produtor rural se acha auto-suficiente, apesar de não ter o conhecimento necessário, tanto na área fiscal, como na área de recursos humanos; e d) grande parte dos produtores dizem não ser necessário aderir à ferramenta contábil gerencial, por acharem que sabem gerenciar, na prática do dia-a-dia; e) transformar a cultura existente quanto às mudanças exigidas pelo atual sistema econômico globalizado; f) omissão das informações por parte dos produtores, e a falta de controle administrativo por parte dos mesmos; g) e por fim a falta de competência dos demais órgãos, em transmitir com clareza as informações necessárias, para esses produtores, por exemplo: Caixa Econômica Federal. Contudo, apesar das dificuldades encontradas pelos escritórios de contabilidade em atender aos produtores rurais, todos os entrevistados, (100\%) responderam que tem sim interesse em buscar recursos que ajudem a expandir os conhecimentos nesta área de Contabilidade Rural, pelo fato de que a maior parte econômica do município concentra-se neste setor, produção 
agropecuária, e também por ser um campo inovador que possibilitam novas oportunidades de renda.

Em se tratando da origem do patrimônio de cada produtor, 40,27\% das respostas, foram que o patrimônio surgiu através de herança familiar; $37,55 \%$ entraram no ramo devido às vantagens oferecidas pelo mercado de trabalho; $14,03 \%$ dos entrevistados gostam do ramo que envolve a atividade pecuária; $8,15 \%$ responderam que entraram na atividade devido a outros motivos, porém, não especificaram o porquê escolheram esta atividade; e por fim nenhum entrevistado respondeu que entrou nesta atividade por falta de conhecimento em outra área, conforme demonstrado na Tabela 02.

Tabela 02 - Origem do Patrimônio, em quantidade e \% de respostas, Tangará da Serra - MT, 2011.

\begin{tabular}{ccc}
\hline ORIGEM & QUANTIDADE & $\%$ \\
\hline Herança familiar & 89 & 40,27 \\
Vantagens oferecidas pelo mercado de trabalho & 83 & 37,55 \\
Gostam do ramo em que envolve a atividade pecuária & 31 & 14,03 \\
Outros motivos & 18 & 8,15 \\
Falta de conhecimento em outra área & 0 & 0,00 \\
\hline \hline Total & 221 & 100 \\
\hline
\end{tabular}

Fonte: Dados da Pesquisa / 2011.

Quanto aos meios na qual é realizado o controle dos acontecimentos ocorridos na propriedade, constatou-se que 5,89\% dos produtores fazem anotações em caderno; 38,91\% realizam o controle por meio de computador; 50,20\% mantêm seu controle através de documentos enviados aos contadores; dentre os demais entrevistados, nenhum deles responderam, que controla e grava tudo na cabeça, ou não faz nenhum controle, conforme mostra a Tabela 03.

Tabela 03 - Controle dos Acontecimentos, em quantidade e \% de respostas, Tangará da Serra - MT, 2011.

\begin{tabular}{crr}
\hline CONTROLE & QUANTIDADE & $\%$ \\
\hline Anotação em caderno & 13 & 5,89 \\
Por meio do computador & 86 & 38,91 \\
Documentos enviados ao contador & 122 & 50,22 \\
Controla e grava tudo na cabeça & 0 & 0,00 \\
Não controla & 0 & 0,00 \\
Outros & 0 & 0,00 \\
\hline \hline Total & 221 & 100 \\
\hline
\end{tabular}

Fonte: Dados da Pesquisa / 2011.

Quando precisa tomar decisões em relação aos negócios da propriedade, 62,89\% dos produtores rurais disseram buscar solucionar o problema conforme a urgência do assunto, 
19,91\% respondeu tentar resolver tudo com rapidez de acordo com as normas contábeis, $17,19 \%$, afirmaram tentar resolver no ato, sem se preocupar com as normas contábeis exigidas, conforme ilustra Tabela 04.

Tabela 04 - Tomadas de Decisões, em quantidade e \% de respostas, Tangará da Serra - MT, 2011.

\begin{tabular}{crr}
\hline TOMADAS DE DECISÕES & QUANTIDADE & $\%$ \\
\hline Na urgência na qual necessita resolver o assunto & 139 & 62,89 \\
Tenta resolver tudo com rapidez, de acordo com as normas contábeis & 44 & 19,92 \\
Tenta resolver no ato, sem se preocupar com as normas contábeis & 38 & 17,19 \\
Faz tudo dentro das normas contábeis, sem se preocupar com o tempo & 0 & 0,00 \\
Outros & 0 & 0,00 \\
\hline \hline Total & 221 & 100 \\
\hline
\end{tabular}

Fonte: Dados da Pesquisa / 2011.

Quanto ao controle das entradas e saídas de dinheiro, a pesquisa constatou que $84,61 \%$ dos entrevistados dizem ter uma planilha própria de controle, e 15,38\% fazem o controle através de livro caixa.

Ao questionar, como é controlado o estoque de cabeças de gado, aproximadamente cerca de $75,56 \%$ dos produtores disseram fazer o controle somente no momento da compra e venda do gado através de emissão de notas, $10,40 \%$ disseram ter controle de seu estoque conforme o desenvolvimento do animal, e 14,02\% afirmaram fazer o controle diariamente, conforme o necessário, assim como ilustra a tabela 05 .

Tabela 05 - Controle de Estoque, em quantidade e \% de respostas, Tangará da Serra - MT, 2011.

\begin{tabular}{crr}
\hline CONTROLE DE ESTOQUE & QUANTIDADE & $\%$ \\
\hline Somente no momento da compra e venda de gado com emissão de nota & 167 & 75,56 \\
É registrado conforme o desenvolvimento do animal & 23 & 10,41 \\
É feito o controle diariamente, conforme necessário & 31 & 14,03 \\
Não faz controle & 0 & 0,00 \\
Outros & 0 & 0,00 \\
\hline \hline Total & 221 & 100 \\
\hline
\end{tabular}

Fonte: Dados da Pesquisa / 2011.

Ao perguntar aos mesmos se eles acreditam que se tivessem mais conhecimento em relação à área contábil, obteriam melhores resultados nos negócios, 16,75\% afirmaram que sim, concordam totalmente, $39,82 \%$ disseram que sim, concordam, 1,35\% opinou por não responder, 30,32\% responderam que não, discordam, e 11,76\% afirmaram que não, discordam totalmente, como ilustrado na tabela 06. 
Tabela 06 - Obter mais conhecimento contábil melhoram os resultados, em quantidade e \% de respostas, Tangará da Serra - MT, 2011.

\begin{tabular}{crr}
\hline CONHECIMENTO CONTÁBIL & QUANTIDADE & $\%$ \\
\hline Sim, concorda totalmente & 37 & 16,75 \\
Sim, concorda & 88 & 39,82 \\
Prefiro não opinar & 3 & 1,35 \\
Não, discorda & 67 & 30,32 \\
Não, discorda totalmente & 26 & 11,76 \\
\hline \hline Total & 221 & 100 \\
\hline
\end{tabular}

Fonte: Dados da Pesquisa /2011.

Analisando o grau de satisfação de cada produtor, referente aos serviços contábeis oferecidos pelo seu contador, 38,01\% afirmaram estar satisfeitos totalmente, 35,30\% disseram somente estar satisfeitos, $21,26 \%$ se mostraram indiferente em relação à pergunta, 5,43\% não estão satisfeitos com o serviço, e nenhum produtor respondeu estar totalmente insatisfeito. Assim sendo ao perguntar se os mesmo estão satisfeitos com os resultados econômicos atingidos pela sua propriedade, 40,27\% informaram estar totalmente satisfeitos, $37,10 \%$ disseram estar somente satisfeitos, 15,84\% foram indiferentes, e 6,79\% não estão satisfeitos com os resultados.

Com relação ao montante de seu patrimônio total, 80,10\% dos produtores disseram saber o valor, porém preferiram não informar, e 19,90\% afirmaram não saber qual o montante total de seu patrimônio.

\subsection{Ferramentas contábeis utilizadas pelas pequenas e médias propriedades pecuárias}

Em relação aos serviços de assessoria contábil utilizados pelos produtores verificou-se que, entre os entrevistados, 66,96\% utilizam ferramentas para fins fiscais e trabalhistas, $23,08 \%$ usufruem de ferramentas somente para fins trabalhistas, e 9,96\% utilizam somente ferramentas fiscais, conforme se pode observar na tabela 07.

Tabela 07 - Serviços Contábeis Utilizados em quantidade e \% de respostas, Tangará da Serra - MT, 2011.

\begin{tabular}{crr}
\hline SERVIÇOS CONTÁBEIS UTILIZADOS & QUANTIDADE & $\%$ \\
\hline Fiscal e Trabalhista & 148 & 66,96 \\
Somente Trabalhista & 51 & 23,08 \\
Somente Fiscal & 22 & 9,96 \\
Fiscal e Gerencial & 0 & 0,00 \\
Outros & 0 & 0,00 \\
\hline \hline Total & 221 & 100 \\
\hline
\end{tabular}

Fonte: Dados da Pesquisa / 2011. 
Ao perguntar aos produtores rurais se eles conheciam e utilizavam algumas ferramenta gerencial, além das fiscais e trabalhistas citadas na questão anterior, muitos disseram obter serviços relacionados à declaração de Imposto de Renda, ITR e CCIR, e para fins gerenciais, tanto na parte administrativa, como no controle de custos.

Quanto às maiores dificuldades de gerenciamento encontradas, 86,87\% afirmaram terem dificuldades, por não possuírem conhecimento o suficiente na área contábil, o que dificulta no processo de tomadas de decisões, e 13,12\% afirmaram deficiência por parte dos contadores em não passar informações adequadas, ou de maneira simplificada, de fácil entendimento, causando assim dificuldades tanto para o produtor, quanto para o contador, como ilustrado na tabela 08.

Tabela 08 - Dificuldades encontradas pelos Produtores, em quantidade e \% de respostas, Tangará da Serra - MT, 2011.

\begin{tabular}{crr}
\hline DIFICULDADES DOS PRODUTORES & QUANTIDADE & $\%$ \\
\hline Falta de conhecimento contábil & 192 & 86,87 \\
Falta de interesse por parte do produtor em relação à área administrativa & 0 & 0,00 \\
Deficiência por parte do contador em não passar informações adequadas & 29 & 13,12 \\
Outros & 0 & 0,00 \\
\hline \hline Total & 221 & 100 \\
\hline
\end{tabular}

Fonte: Dados da Pesquisa / 2011.

Logo, ao questionar os mesmo, se eles adotariam outro modelo de planilha para controles gerenciais mais simples e de fácil entendimento todos responderam que sim, caso vissem que a sugestão feita fosse mais vantajosa e prática, e também acreditam que com auxílio adequado de um profissional de contabilidade, que ajude tanto no gerenciamento da propriedade, quanto no controle, o desenvolvimento econômico e operacional da propriedade pode melhorar. Os entrevistados também disseram estar dispostos a pagar para que um profissional os auxiliem no gerenciamento dos negócios da propriedade, porém ao perguntar quanto pagariam 80,99\% responderam que pagariam proporcional aos serviços recebidos, e 19,01\% disseram que pagaria um salário mínimo mensal ( $\mathrm{R} \$ 545,00)$, de acordo com a tabela 09. 
Tabela 09 - Valor disposto a ser pago pelos produtores, em quantidade e \% de respostas, Tangará da Serra - MT, 2011.

\begin{tabular}{crr}
\hline VALOR A SER PAGO & QUANTIDADE & $\%$ \\
\hline Proporcional aos benefícios recebidos & 179 & 80,99 \\
R \$ 545,00 (um salário mínimo) & 42 & 19,01 \\
R\$ 1.090,00 (dois salários mínimos) & 0 & 0,00 \\
Outros & 0 & 0,00 \\
\hline \hline Total & 221 & 100 \\
\hline
\end{tabular}

Fonte: Dados da Pesquisa / 2011.

\subsection{Ferramentas contábeis que os escritórios contábeis oferecem aos produtores.}

Em relação ao tipo de assessoria contábil prestados pelos escritórios contábeis, todos os entrevistados disseram prestar assessoria utilizando ferramentas gerenciais como tributária ou escrituração completa, recursos humano, fluxo de caixa, controle gerencial e apenas $17,94 \%$ disseram prestar assessoria com ferramentas de custos, sendo que deste percentual de escritórios que oferecem a ferramenta de custo, todos os entrevistados afirmaram que nenhum produtor usufrui, ou faz uso desta ferramenta tão importante apontada pela literatura.

De acordo com os dados da pesquisa verificou-se através dos escritórios contábeis que, 25,34\% dos produtores rurais do município de Tangará da Serra - MT utilizam a escrituração completa, e que os serviços mais procurados pelos produtores são de origem fiscal, trabalhista, declaração de Imposto de Renda, ITR e CCIR.

\section{CONSIDERAÇÕES FINAIS}

De natureza exploratória, este artigo teve por objetivo contribuir para demonstrar quais as principais ferramentas gerencias utilizada tanto por produtores rurais de pequeno e médio, como por escritórios contábeis. Permitindo assim, através da informação contábil, o planejamento e o controle orçamentário nessas propriedades. A questão chave imposta, inicialmente, é a seguinte: quais as ferramentas gerenciais utilizadas na atividade pecuária de pequenas e médias propriedades do município de Tangará da Serra - MT?

Pode-se concluir, então que, a contabilidade gerencial nestas propriedades são pouco utilizadas, e os serviços ou ferramentas mais utilizadas são para fins tributários, trabalhistas, declarações, etc. Também fica claro e evidente a deficiência na qualificação dos escritórios contábeis em relação a profissionais, especializados nesta área, o que dificulta o processo.

Conclui-se também, que os escritórios de contabilidade encontram resistências por parte dos produtores em adotar a contabilidade como ferramenta gerencial, na qual visa controlar e 
planejar o seu negócio, pois a contabilidade é vista pelos mesmos como uma barreira que dificulta o processo e não como uma ferramenta para auxiliar os gestores.

Por isso, este artigo pode contribuir para debates e desafios dessa dinâmica ferramenta, desencadeando muita discussão sobre o tema exposto.

\section{REFERÊNCIAS}

ANCELES, Pedro Einstein dos Santos. Manual de tributos da atividade rural. São Paulo: Atlas, 2001.

BATALHA, Mário Otávio. Gestão agroindustrial: GEPAI: Grupo de estudos e pesquisas agroindustriais. 5 ed. São Paulo: Atlas, 2009.

BATALHA, Mário Otávio, et al. Recursos humanos e agronegócio: a evolução do perfil profissional. Editora Novos Talentos, 2005.

BOTH, Sérgio José; SIQUEIRA, Claudineide Julião de Souza. Metodologia Científica: Faça fácil sua pesquisa. Tangará da Serra. São Francisco, 2004.

BRASIL. Lei $\mathbf{n}^{\circ} \mathbf{8 . 0 2 3}$, de 15-3-1990. Altera a legislação do imposto de renda sobre o resultado da atividade rural e dá outras providências. Disponível em: <http://www.planalto.gov.br/ccivil_03/leis/L8023.htm>. Acesso em: 16 set. 2011.

BRASIL. Lei $\mathbf{n}^{\circ}$ 9.249, de 26-12-1995. Altera a legislação do imposto de renda das pessoas jurídicas, bem como da contribuição social sobre o lucro líquido, e dá outras providências. Disponível em: < http://www.receita.fazenda.gov.br/legislacao/leis/ant2001/lei924995.htm>. Acesso em: 21 set. 2011.

BRASIL. Lei $\mathbf{n}^{\circ}$ 9.393, de 19-12-1996. Dispõe sobre o Imposto sobre a Propriedade Territorial Rural - ITR, sobre pagamento da dívida representada por Títulos da Dívida Agrária e dá outras providências. Disponível em: <http://www.planalto.gov.br/ccivil_03/leis/L9393.htm>. Acesso em: 07 set. 2011.

BRASIL. Lei $\mathbf{n}^{\circ}$ 5172, de 25-10-1966. Dispõe sobre o Sistema Tributário Nacional e institui normas gerais de direito tributário aplicáveis à União, Estados e Municípios. Disponível em: <http://www.planalto.gov.br/ccivil_03/leis/L5172.htm>. Acesso em: 08 ago. 2011.

BRASIL. Decreto-lei $\mathbf{n}^{\circ}$ 902, de 30-09-1969. Dispõe sobre a forma de tributação dos rendimentos da exploração agrícola ou pastoril e dá outras providências. Disponível em: < http://www.jusbrasil.com.br/legislacao/126022/decreto-lei-902-69>. Acesso em: 14 set.. 2011.

BRASIL. Decreto-lei $\mathbf{n}^{\circ}$ 57, de 18-11-1966. Altera dispositivos sobre lançamento e cobrança do Imposto sobre a Propriedade Territorial Rural, institui normas sobre arrecadação da Dívida Ativa correspondente, e dá outras providências. Disponível em: < http://www010.dataprev.gov.br/sislex/paginas/24/1966/57.htm>. Acesso em: 07 set. 2011. 
BRASIL. Lei $\mathbf{n}^{\circ} \mathbf{6 . 7 4 6}$, de 10-12-1979. Altera o disposto nos arts. 49 e 50 da Lei $n^{\circ} 4.504$, de 30 de novembro de 1964 ( Estatuto da Terra ), e dá outras providências. Disponível em: < http://www.jusbrasil.com.br/legislacao/anotada/2388926/lei-6746-79>. Acesso em: 05 set. 2011.

BRASIL. Decreto-lei $n^{\circ}$ 1.959, de 14-09-1972. Altera o inciso XIV do artigo $4^{\circ}$ da Lei $n^{\circ}$ 4.595, de 31 de dezembro de 1964. Disponível em: < http://www.jusbrasil.com.br/legislacao/anotada/2877045/decreto-lei-1959-82>. Acesso em: 11 set. 2011.

BRASIL. Decreto-lei $\mathbf{n}^{\circ}$ 1.166, de 15-04-1971. Dispõe sobre enquadramento e contribuição sindical rural. Disponível em: $<$ http://www.jusbrasil.com.br/legislacao/111101/decreto-lei1166-71>. Acesso em: 11 set. 2011.

BRASIL. Lei $\mathbf{n}^{\circ}$ 8.315, de 23-12-1991. Dispõe sobre a criação do Serviço Nacional de Aprendizagem Rural (Senar) nos termos do art. 62 do Ato das Disposições Constitucionais Transitórias. Disponível em:< http://www.jusbrasil.com.br/legislacao/anotada/2772921/lei8315-91>. Acesso em: 10 set. 2011.

CALDERELLI, Antonio. Enciclopédia contábil e comercial brasileira. 28 ed. São Paulo: CETEC, 2003.

CREPALDI, Silvio Aparecido.Contabilidade rural: uma abordagem decisorial. 3 ed. São Paulo: Atlas, 2005.

HORNGREN, C. T.; et al. Cost accounting: a managerial emphasis. New Jersey: PrenticeHall, 1999.

MATOS, Aroldo Gomes de. ICMS: comentários à LC 87/96. São Paulo: Dialética, 1997.

MARION, José Carlos. Contabilidade Rural: contabilidade agrícola, contabilidade da pecuária, imposto de renda pessoa jurídica. 8 ed. São Paulo: Atlas, 2005.

MARION, José Carlos. Contabilidade e controladoria em Agribusiness. 1 ed. São Paulo: Atlas, 1996.

MARTINOVICH, M. Como gerenciar o capital de giro. Agenda do empresário, São Paulo, no 11, p. 1-6,1996.

MARTINS, Eliseu; ROCHA, Welington.Contabilidade de Custos. 3ed. São Paulo: Atlas, 1987.

MEGLIORINI, Evandir. Custos: análise e gestão. 2. Ed.São Paulo: Pearson Prentice Hall, 2007

MELZ, Laércio Juarez. Competitividade da cadeia produtiva de carne de frango em Mato Grosso: Avaliação dos Segmentos de avicultura e processamento. 2010. 44 p. Dissertação (Mestrado em Engenharia de Produção) - Centro de Ciências Exatas e Tecnologia, Universidade Federal de São Carlos, Santa Catarina. 
NEPOMUCENO, Fernando. Contabilidade rural e seus custos de produção. São Paulo: IOB - Thomson, 2004.

SANTOS, G. J. dos; MARION, J.C., SEGATTI, S. Administração de custos na agropecuária. 3 ed. São Paulo: Atlas, 2002. 